\title{
SYSTEM TRÓJWYMIAROWEJ TOMOGRAFII POJEMNOŚCIOWEJ W ZASTOSOWANIU DO WYZNACZANIA UDZIALU FAZ ORAZ IDENTYFIKACJI STRUKTUR W PRZEPLYWACH MIESZANIN GAZ-CIECZ
}

\author{
Robert Banasiak ${ }^{1}$, Radoslaw Wajman ${ }^{1}$, Henryk Fidos ${ }^{2}$, Paweł Fiderek ${ }^{1}$, Tomasz Jaworski ${ }^{1}$, \\ Jacek Nowakowski ${ }^{1}$, Dominik Sankowski ${ }^{1}$ \\ ${ }^{1}$ Instytut Informatyki Stosowanej Politechniki Łódzkiej, ${ }^{2}$ Katedra Inżynierii Chemicznej Politechniki Łódzkiej
}

Streszczenie. W procesach przemysłowych, w których bezpośrednie monitorowanie jest utrudnione, zastosowanie nieinwazyjnego systemu tomografii pojemnościowej dla identyfikacji struktur przepływów dwufazowych mieszanin gaz-ciecz oraz wyznaczenia udziatu faz jest szczególnie ważne. W artykule przedstawiono wyniki badań poświęconych rozwojowi nowych nieinwazyjnych metod identyfikacji $i$ wizualizacji struktur przeplywów dwufazowych. Nowe możliwości, jakie niesie ze soba zastosowanie komputerowych technik tomograficznych w pomiarach wielkości elektrycznych, wyznaczają dziś standardy w pomiarach dynamicznych. Proponowane rozwiazanie zakłada możliwość zastosowania systemu tomograficznego do pomiaru rozkładu koncentracji poszczególnych frakcji procesu. Opracowane algorytmy pozwolity na szybka trójwymiarowa wizualizację wnętrza rurociagów, w których występuja przeplywy mieszanin gaz-ciecz, poprzez uzyskanie w krótkim czasie obrazów oraz ich szybka analizę i identyfikację. Taka diagnostyka może być użyteczna w kontekście przemysłowych procesów monitorowania oraz sterowania przeplywami mieszanin gaz-ciecz w systemach czasu rzeczywistego.

Słowa kluczowe: elektryczna tomografia pojemnościowa, trójwymiarowa wizualizacja, przepływ dwufazowy, mieszaniny gaz-ciecz, udział faz, struktury przepływu

\section{APPLICATION OF 3D ELECTRICAL CAPACITANCE TOMOGRAPHY FOR PHASE FRACTION DETERMINATION AND STRUTURES IDENTIFICATION IN TWO-PHASE FLOWS}

\begin{abstract}
In the industrial processes, where the direct monitoring is difficult, the application of the non-invasive electrical capacitance tomography system for the two-phase gas-liquid mixtures flow structures identification and the phase distribution calculation is of great importance. This paper presents the research results of development new non-invasive diagnostic methods. The new possibilities offered by the tomographic techniques applications for the purposes of the electrical quantities measurement, define today the standards of dynamic measurements. The proposed solution involves the possibility of applying the tomographic system to measure the fractions concentration distribution of the flow. The designed algorithms allowed the fast $3 D$ visualization of the pipeline interior through the quick tomographic image reconstruction and their analysis and structure identification. The obtained diagnostic data could be useful in the context of monitor and control of the flow industrial facilities in the real time.
\end{abstract}

Keywords: electrical capacitance tomography, three-dimensional visualization, two-phase flow, gas-liquid mixtures, phase fraction, flow structures

\section{Wprowadzenie}

Badania opisane w artykule odnoszą się do zakończonego projektu naukowo - badawczego, którego celem było opracowanie systemu pomiarowego do identyfikacji struktur oraz wyznaczania udziału faz przepływu dwufazowego mieszanin gaz-ciecz w oparciu o trójwymiarową tomografię pojemnościową 3D ECT (ang. three dimensional electrical capacitance tomography) [6, 9]. Założeniem projektu było zbudowanie urządzenia posiadającego możliwości nieinwazyjnego monitorowania i diagnozowania procesów przepływowych, które znajdują szerokie zastosowania w przemyśle budowlanym, spożywczym, farmaceutycznym, chemicznym, rafineryjnym i wielu innych.

W ramach zrealizowanych prac badawczych dokonano oceny własności metrologicznych prototypowego systemu trójwymiarowej elektrycznej tomografii pojemnościowej w zastosowaniu do nieinwazyjnego wyznaczania udziału faz oraz identyfikacji struktur $\mathrm{w}$ przepływach dwufazowych mieszanin gaz-ciecz, w rurociągach pionowych i poziomych [6, 12]. Istota proponowanego rozwiązania polegała na zastosowaniu nowatorskiej, przestrzennej konstrukcji czujnika pojemnościowego o elektrodach wewnętrznych [4], systemu pomiarowego tomografii pojemnościowej 3D oraz specjalizowanych algorytmów równoległego, szybkiego przetwarzania danych pomiarowych do wizualizacji wnętrza fragmentu przepływu mieszanin gaz-ciecz $[1,5]$.

\section{Przepływy mieszanin gaz - ciecz}

$\mathrm{W}$ procesach przemysłowych, w których jest utrudnione bezpośrednie monitorowanie, zastosowanie tomografii pojemnościowej do identyfikacji przepływów mieszanin gaz-ciecz oraz wyznaczenia udziału faz jest szczególnie ważne. Istnieją przepływy, które przebiegają w nieprzeźroczystych profilach zamkniętych - umieszczenie klasycznych czujników wewnątrz takiej instalacji jest zwykle niemożliwe lub niekorzystnie wpływa na przebieg procesu. Stosowane do tej pory metody określania struktur przepływów mieszanin gaz-ciecz wymagały wiercenia otworów w ścianach rurociągów, a sposoby obliczania udziału faz wymagały korzystania $\mathrm{z}$ technik opartych na błyskawicznym zatrzymywaniu porcji przepływającej mieszaniny (zamykaniu szybkich zaworów usytuowanych na rurociągu) [2, 3, 7].

Przepływy dwufazowe mieszanin gaz-ciecz stanowią istotną część wielu procesów przemysłowych jak chociażby procesy aeracji, które zachodzą $\mathrm{w}$ instalacjach przemysłowych reaktorów chemicznych, aparaty do flotacji oraz urządzenia do napowietrzania wody czy ścieków. Zadaniem urządzeń natleniających jest wytworzenie właściwej proporcji pomiędzy ciecza i tlenem. Wprowadzenie gazu do cieczy może również wywoływać cyrkulacje, intensyfikujące proces wymiany masy. Jednym z podstawowych zagadnień jest ocena powierzchni międzyfazowej - parametr ten ma, bowiem bezpośredni wpływ na wymianę ciepła i masy.

Przykładem napowietrzania wody i ścieków mogą być biologiczne oczyszczalnie ścieków. Istotną rolę w tych procesach odgrywają bakterie tlenowe (aerobowe), które rozwijają się tylko $\mathrm{w}$ obecności wolnego tlenu $\mathrm{z}$ powietrza atmosferycznego lub rozpuszczonego $\mathrm{w}$ wodzie, a stopień napowietrzania powinien mieścić się $\mathrm{w}$ określonym przedziale, zależnym od temperatury wody. Jednym ze sposobów napowietrzania jest wprowadzenie do układu, sprężonego powietrza i wymuszanie swobodnego przepływu pęcherzyków w górę słupa cieczy. Dwufazowe procesy przepływowe wysteppuja również w kolumnach barbotażowych. Ich przeznaczeniem jest realizacja różnych procesów fizykochemicznych. Kontrolując wielkość powierzchni międzyfazowej i udział faz często decyduje się o intensywności przebiegania tych procesów. Dla przykładu w kolumnach typu air-lift oraz eżektorach, ruch cieczy wymuszany jest właśnie strumieniem wprowadzanego gazu. Urządzenia takie powszechnie stosowane sa w przemyśle wydobywczym (np. procesy flotacji) lub do wytrącania pewnych frakcji z cieczy w procesach sedymentacji, np. odtłuszczania, gdzie istotna jest rozmiar pęcherzyków. Oddzielną grupę stanowią procesy, w których pęcherzyki gazu mogą powstawać w cieczy w wyniku reakcji chemicznych. 
Ma to miejsce np. w reaktorach chemicznych czy w procesach elektrolizy, wktórych faza gazowa jest produktem (często ubocznym) reakcji chemicznej. Wówczas pojawianie się pęcherzyków świadczy o jakości zachodzących przemian, a pomiar wielkości pęcherzyków dostarcza informacji o przebiegu procesu. Istnieją też procesy, $w$ których pojawienie się pęcherzyków jest niepożądane np. wymienniki ciepła lub urządzenia grzewcze, gdzie pojawienie się gazu świadczy o niepożądanym wrzeniu cieczy i wymusza sygnalizację stanu awaryjnego. Podobnie jest w przypadku zjawisk kawitacji np. w pompach wirowych. Zjawiska te powodowane są szybkim obniżeniem ciśnienia poniżej wartości, w której rozpoczyna się wrzenie cieczy. Jest to zjawisko niepożądane, ponieważ prowadzi do erozji łopatek pompy. Zjawisko to może też świadczyć braku szczelności układu.

\section{Koncepcja systemu pomiarowego 3D ECT}

W trakcie realizacji prac badawczych autorzy opracowali i zaimplementowali nieinwazyjny system trójwymiarowej tomografii pojemnościowej, wyposażony w nowy rodzaj przestrzennego czujnika pojemnościowego. W ramach prac autorzy skonstruowali nowy system pomiarowy. To zadanie wymagało:

- zaprojektowania czujnika o przestrzennym rozmieszczeniu elektrod na wewnętrznych ścianach rurociągu;

- opracowania protokołu pomiarowego;

- zastosowania architektury równoległej dla potrzeb szybkiego przetwarzania danych pomiarowych oraz rekonstrukcji i identyfikacji przepływu;

- opracowania i zaimplementowania nowych algorytmów, pozwalających na uzyskanie jakościowo lepszych obrazów tomograficznych 3D, dotyczących:

o rekonstrukcji obrazów i kształtów uwzględniających nieliniowy charakter pola elektrycznego;

o optymalizacji symulowanego rozkładu wrażliwości we wnętrzu modelu czujnika;

o wspomagania nieliniowego procesu rekonstrukcji obrazów $3 \mathrm{D}$

- opracowania nowych metod pozwalających oceniać i klasyfikować przepływ na podstawie obrazów tomograficznych.

Zaproponowane rozwiązanie umożliwia szybką identyfikację przepływów dwufazowych mieszanin gaz-ciecz w rurociągach. Uzyskane wyniki identyfikacji uwzględniają specyfikę zjawisk fizycznych zachodzących w sekcjach poziomych i pionowych rurociągu. Autorzy zastosowali w swoim systemie szereg nowych rozwiązań, które wymagały opracowania algorytmów przetwarzających dane pomiarowe. W wyniku prowadzonych badań opracowane zostały metody pozwalające na szybką rekonstrukcję dobrej jakości obrazów tomograficznych 3D. Wykorzystano do tego równoległą architekturę obliczeniową łączącą w sobie technologie Nvidia CUDA oraz OpenCL. Opracowana architektura zapewnia zasadniczy wzrost szybkości obliczeń dzięki wykorzystaniu mocy układów procesorów graficznych. Zrekonstruowane obrazy zostały poddane procesowi identyfikacji struktur przepływu mieszanin gaz-ciecz przy pomocy algorytmów klasteryzacji rozmytej.

\section{Zakres badań naukowych}

Prace badawcze ukierunkowane były na zastosowanie systemu pomiarowego tomografii pojemnościowej do wizualizacji i identyfikacji przepływów mieszanin gaz-ciecz ze szczególnym uwzględnieniem:

- oceny metrologicznej przydatności systemu ECT 3D do monitorowania przepływów mieszanin mediów charakteryzujących się znaczną różnicą wartości względnych stałych elektrycznych, obejmującą:

o optymalizację struktury czujnika pojemnościowego ECT o przestrzennym rozkładzie elektrod pod względem jego możliwości skanowania procesu przepływu mieszanin gaz-ciecz;

o metrologiczną ocenę dokładności rekonstrukcji obrazu na bazie danych pomiarowych i symulacji;

o metrologiczną ocenę identyfikacji struktur przepływu $\mathrm{w}$ porównaniu $\mathrm{z}$ innymi metodami: metodą szybkozamykających się zaworów oraz metodą identyfikacji struktury przepływu przy pomocy kamery CCD;

- zbadania możliwości zastosowania akceleracji sprzętowej przy przetwarzaniu danych pomiarowych oraz rekonstrukcji i identyfikacji przepływu;

- opracowanie nowych metod komputerowych pozwalających na uzyskanie lepszych jakościowo tomogramów 3D, dotyczących:

o algorytmów rekonstrukcji obrazów i kształtów uwzględniających nieliniowy charakter pola elektrycznego;

o algorytmów optymalizacji symulowanego rozkładu wrażliwości wewnątrz modelu czujnika;

o algorytmów wspomagających nieliniowy proces rekonstrukcji obrazów przestrzennych oraz kształtów,

- opracowanie nowych metod komputerowych pozwalających oceniać i klasyfikować przepływ na podstawie obrazów tomograficznych.

Wszystkie prace badawcze zrealizowane były w Laboratorium Tomografii Procesowej im. Prof. Tomasza Dyakowskiego, zbudowanym w latach 2007 - 2010 w Instytucie Informatyki Stosowanej PŁ [8], w którego skład wchodzi instalacja przepływu dwufazowego. Zakres wykonanych prac przedstawiono w postaci diagramu zamieszczonego na rysunku 1 . Prace badawcze zostały pogrupowane w bloki, odzwierciedlające kolejne fazy projektu. Na diagramie zamieszczono zarówno zadania przygotowawcze (ramki w kolorze niebieskim: opracowanie stanowiska optymalizacji czujników pojemnościowych, budowę, konfigurację i oprogramowanie komputera wysokiej mocy obliczeniowej oraz opracowanie i implementację nowego typu macierzy wrażliwości opartej na śledzeniu powierzchni ekwipotencjalnych [10]), zadania fazy algorytmiczno-eksperymentalnej (ramki w kolorze pomarańczowym: opracowanie i budowa zestawu czujników pojemnościowych, przygotowanie stanowiska pomiarowego [13], opracowanie i implementacja algorytmów przetwarzania i analizy danych pomiarowych oraz obrazów 3D, przeprowadzenie serii pomiarowych [13]) oraz faza końcowa projektu (ramki w kolorze zielonym: analiza i identyfikacja przepływu, charakterystyka [4] i porównanie wyników identyfikacji, ocena metrologiczna [12]).

\section{Podsumowanie}

Przeprowadzone badania naukowe pozwoliły opracować nowe nieinwazyjne metody identyfikacji i wizualizacji struktur przepływów dwufazowych. Przedstawione techniki i algorytmy pozwoliły na szybką przestrzenną wizualizację $\mathrm{w}$ czasie rzeczywistym wnętrza rurociągów, w których zachodzą przepływy mieszanin gaz-ciecz. Otrzymane obrazy dają możliwość szybkiej analizy i identyfikacji, co może być użyteczne w przemysłowych procesach monitorowania oraz sterowania przepływami mieszanin gaz-ciecz. Opracowana metoda identyfikacji i wizualizacji przepływów dwufazowych, przy zastosowaniu tomografii pojemnościowej, może znaleźć praktyczne zastosowanie w wielu gałęziach gospodarki, gdzie powszechnie pojawiają się przepływy mieszanin gaz-ciecz np.: w przemyśle chemicznym, farmaceutycznym, wydobywczym, energetycznym, odlewniczym, spożywczym i wielu innych. 


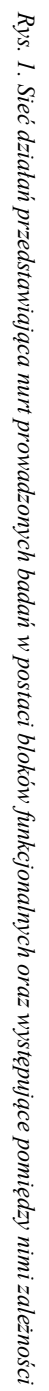
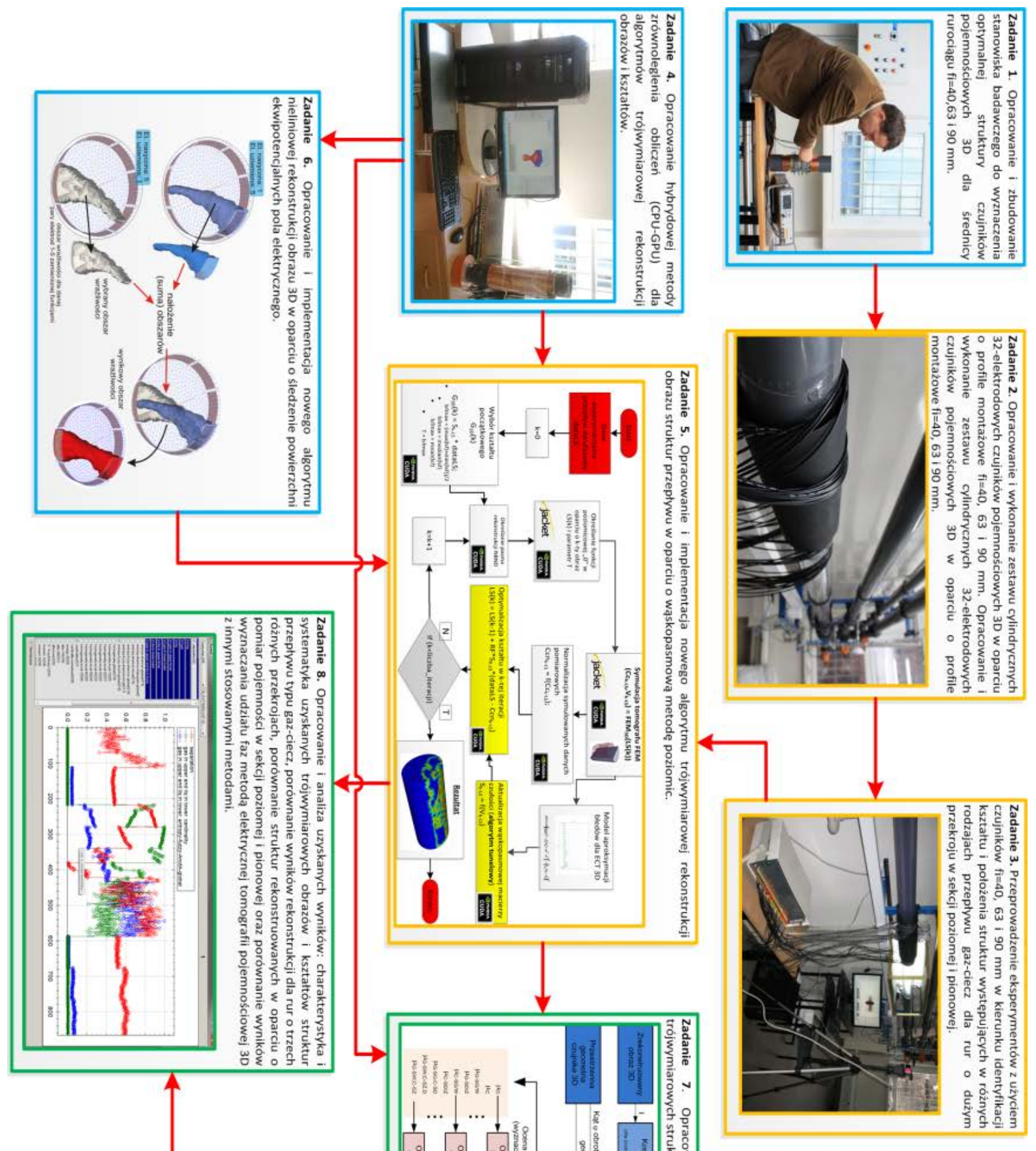
Rosnące potrzeby przemysłu w zakresie nieskomplikowanej, relatywnie taniej, nieinwazyjnej i szybkiej metody sterowania procesami przepływów wielofazowych w rurociągach poziomych i pionowych, uzasadniają realizację podjętych tematów badawczych. Akwizycja obrazu oraz identyfikacja rodzaju przepływu dwufazowych mieszanin gaz-ciecz, w czasie rzeczywistym jest bardzo istotna przy monitorowaniu instalacji przemysłowych, a także $\mathrm{w}$ badaniach numerycznych przy weryfikacji wyników.

Ciągłe monitorowanie i diagnozowanie zachodzących procesów przepływowych może stanowić istotną informację o ich przebiegu i ewentualnych nieprawidłowościach oraz umożliwić ich ciągłe automatyczne kontrolowanie i sterowanie. W konsekwencji pozwoli to na zapobieganie awariom systemów przemysłowych. Zrealizowane badania naukowe przyczyniły się do tego, iż macierzyste jednostki autorów, Instytut Informatyki Stosowanej PŁ jak również Katedra Inżynierii Chemicznej PŁ, wzbogaciły swoją ofertę $\mathrm{w}$ zakresie nieinwazyjnych systemów diagnostycznych dla procesów przepływowych dedykowaną do szerokiej gamy przedstawicieli przemysłu.

\section{Podziękowania}

Prace opisane w ramach niniejszego artykułu są finansowane z rządowego projektu naukowo-badawczego NCN nr 4664/B/T02/2010/38

\section{Literatura}

[1] Banasiak R, Nowakowski J., Sankowski D.: Feasibility study of GPU supercomputing approach for solving 3D ECT forward and inverse problem, Proceedings of 6th International Symposium on Process Tomography, 26-28 march, 2012, Cape Town (RPA)

[2] Dziubiński M., Fidos H., Sosno M., The flow pattern map of two-phase nonNewtonian liquid-gas flow in the vertical pipe, Int. J. Multiphase Flow (2004), 29, 132.

[3] Hewitt, G.F., Roberts, D.N.: Studies of Two-Phase Flow Patterns by Simultaneous X-ray and Flash Photography, AERE-M 2159, HMSO, (1969).

[4] Jaworski T., Fiderek P., Wajman R., Banasiak R.: Identyfikacja przepływu dwufazowego gaz-ciecz oparta na ocenie rozmytej obrazów tomograficznych 3D. IAPGOS, 2013, nr 3, 41-48.

[5] Kapusta P., Banasiak R., Sankowski D.: Efficient computation of linearized inverse problem for 3D electrical capacitance tomography using GPU and CUDA technology, XVII International Conference on Information Technology Systems theory, design, implementations, applications, Lodz, November $3-4$, 2010.

[6] Marashdeh Q., Wang F, Fan L.S., Warsito, W.: Velocity Measurement of MultiPhase flows Based on Electrical Capacitance Volume Tomography, Sensors, (2007) IEEE, pp. 1017-1019.

[7] Oshinowo T., Charles M.E.: Vertical two-phase flow. Part I. Flow pattern correlations, The Canadian. J. Chem. Engng, 1974, 52, 25-35.

[8] Sankowski D.: Laboratorium tomografii procesowej im. prof. Tomasza Dyakowskiego w Katedrze Informatyki Stosowanej. Zeszyty naukowe politechniki łódzkiej, seria: Elektryka, 2010, rocznik 1078, nr 121, s. 67-75.

[9] Soleimani M., Wang H., Li Y, Yang W., A Comparative Study Of Three Dimensional Electrical Capacitance Tomography, International Journal For Information Systems Sciences, 2007, Vol.3, No.2.

[10]Wajman R., Banasiak R.: Nowa metoda tunelowego wyznaczania macierzy wrażliwości dla potrzeb procesu rekonstrukcji obrazów dla trójwymiarowej tomografii pojemnościowej. IAPGOS, 2013, nr 3, 32-37.

[11] Wajman R., Banasiak R., Jaworski T., Fidos H.: Three-dimensional Sensor for Electrical Capacitance Tomography System with the Internal Electrodes, Zeszyty naukowe AGH - Automatyka 15/3 2011, s. 571-582.

[12]Wajman R., Fidos H., Fiderek P., Jaworski T., Nowakowski J., Sankowski D., Banasiak R.: Ocena metrologiczna systemu pomiarowego dla potrzeb wyznaczania udziału faz w przepływie mieszanin gaz-ciecz metoda tomografii pojemnościowej 3D. IAPGOS, 2013, nr 3, 49-54

[13] Wajman R., Jaworski T., Fiderek P., Banasiak R.: Algorytm dystrybucji znaczników czasowych dla potrzeb synchronizacji danych z różnych systemów pomiarowych. IAPGOS, 2013, nr 3, 38-40.
Dr inż. Robert Banasiak

e-mail: robert.banasiak@p.lodz.pl

Dr inż. Robert Banasiak jest adiunktem w Instytucie Informatyki Stosowanej Politechniki Łódzkiej. W swoich pracach zajmuje się przemysłowymi zastosowaniami elektrycznej tomografii procesowej, a W szczególności problematyką rekonstrukcji obrazów oraz modelowania numerycznego systemów tomografii pojemnościowej. Kierownik grantu 4664/B/T02/2010/38.

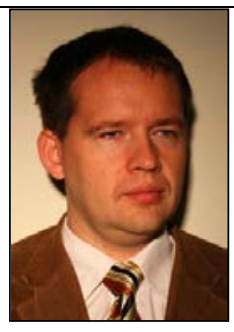

\section{Dr inż. Radosław Wajman}

e-mail: rwajman@kis.p.lodz.pl

Dr inż. Radosław Wajman jest adiunktem w Instytucie Informatyki Stosowanej Politechniki Łódzkiej. Prowadzone badania skupiaja się nad zastosowaniem systemów trójwymiarowej tomografii pojemnościowej do nieinwazyjnego monitorowania, diagnozowania oraz automatycznego sterowania pracą przemysłowych instalacji transportu pneumatycznego materiałów sypkich oraz przepływu dwu-fazowego gaz-ciecz.

\section{Dr inż. Henryk Fidos \\ e-mail: henryk.fidos@p.lodz.pl}

Dr inż. Henryk Fidos w roku 1975 ukończył studia w Instytucie Inżynierii Chemicznej Politechniki Łódzkiej. Jest adiunktem w Katedrze Inżynierii Chemicznej Wydziału Inżynierii Procesowej i Ochrony Środowiska tej uczelni. Specjalność inżynieria chemiczna i procesowa, mechanika płynów, przepływy wielofazowe, reologia i reometria płynów nienewtonowskich.

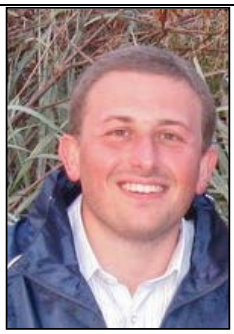

\section{Mgr inż. Pawel Fiderek}

e-mail: p.fiderek@kis.p.lodz.pl

Mgr inż. Paweł Fiderek jest doktorantem w Instytucie Informatyki Stosowanej Politechniki Łódzkiej. W swoich pracach zajmuje się zagadnieniami związanymi $\mathrm{z}$ tomografią komputerowa, rozpoznawaniem obrazów oraz sztuczną inteligencją zwłaszcza logiką rozmytą.

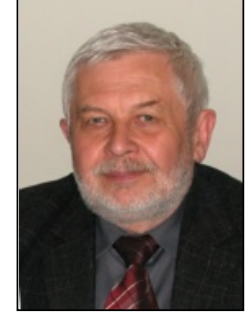

\section{Mgr inż. Tomasz Jaworski}

e-mail: tjaworski@kis.p.lodz.pl

Mgr inż. Tomasz Jaworski jest doktorantem w Instytucie Informatyki Stosowanej Politechniki Łódzkiej. W swoich pracach zajmuje się zagadnieniami związanymi $\mathrm{z}$ logika rozmyta oraz

przetwarzaniem obrazów.

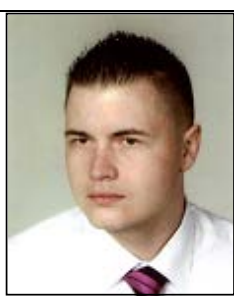

\section{Dr inż. Jacek Nowakowski}

e-mail: jacnow@kis.p.lodz.pl

Dr inż. Jacek Nowakowski jest adiunktem w Instytucie Informatyki Stosowanej Politechniki Łódzkiej. Tematyka realizowanych prac naukowych obejmuje zagadnienia dotyczące pomiarów jak również sterowania przepływami wielofazowymi z wykorzystaniem wielomodalnych metod tomograficznych. W ramach grantu Maria Curie DENIDIA prowadził badania na Uniwersytecie w Bergen.

\section{Prof. dr hab. inż. Dominik Sankowski}

e-mail: dsan@kis.p.lodz.pl

Prof. Sankowski jest dyrektorem Instytutu Informatyki Stosowanej Politechniki Łódzkiej. W ramach prac badawczych zorganizował zespoły naukowe w dziedzinach: przetwarzania, rozpoznawania i analizy obrazów, tomografii procesowej, inżynierii oprogramowania, implementacji technik i metod sztucznej inteligencji, a także automatycznej identyfikacji i regulacji obiektów przemysłowych w systemach czasu rzeczywistego. Aktualna działalność naukowa prof. D. Sankowskiego obejmuje również tematykę związaną $\mathrm{z}$ informatyzacją jednostek administracji samorządowej. 